\title{
Study of the effect of chopping on the adhesion of codeposited mixed thin films
}

\author{
VIJAYA PURI and R K PURI* \\ Department of Physics, * Department of USIC, Shivaji University, Kolhapur 416004, India \\ MS received 1 July 1994; revised 16 January 1995

\begin{abstract}
This paper reports adhesion of codeposited mixed films of $\mathrm{Cu}-\mathrm{Ag}, \mathrm{Cu}-\mathrm{Al}$, $\mathrm{MgF}_{2}-\mathrm{ZnS}$ and $\mathrm{MgF}_{2}-$ cryolite and enhancement of adhesion by chopping technique. Results indicate that codeposited mixed films show higher adhesion than single films and chopping improves the adhesion further. The quenching of crystal growth seems to be more effective if two materials are codeposited and chopped. Chopping along with mixing increases the number of nucleation sites and decreases defects in the film. Decreasing defects and modifying the microstructure increases the adhesion of the films. Chopping also seems to increase oxygen affinity of both metallic and dielectric films for growth of interfacial bonding layer.
\end{abstract}

Keywords. Chopping; codeposition; mixed films; adhesion; non-chopped.

\section{Introduction}

Metallic and dielectric films are widely used in microelectronics and optical thin film systems. The designers of these systems have a very limited selection of materials. Mixed films offer a wider choice of materials. The most direct method is to prepare a mixture of the materials and deposit from a single source (Hiradayanath et al 1979; Vankar et al 1979; Ganner 1986). Simultaneous evaporation using several sources (Jacobson 1966) is a very flexible method. Our work (Vijaya et al 1980, 1987; Puri et al 1983) on codeposited mixed $\mathrm{MgF}_{2}$-cryolite films has shown the superiority of chopped mixed films over single films.

In order to be functional the thin film has to be adherent to the substrate. Various methods like deposition on hot substrate (Pulkar 1982; Martin et al 1983; Pierce and Vaugham 1983), deposition in presence of plasma or glow discharge cleaning (Stoddart et al 1970; Fancey and Mathews 1990; Pulkar et al 1990), deposition of bonding layer (Mattox 1973), etc have been reported to increase the adhesion of the films.

This paper reports the adhesion of codeposited mixed films of $\mathrm{Cu}-\mathrm{Ag}, \mathrm{Cu}-\mathrm{Al}$, $\mathrm{MgF}_{2}-\mathrm{ZnS}$ and $\mathrm{MgF}_{2}-$ cryolite and the effect of chopping (Vijaya et al 1980) on the adhesion of these films.

\section{Experimental}

Both metallic and dielectric films were deposited on glass by thermal evaporation $(\sim 7 \AA / s)$ in a vacuum of better than $8 \times 10^{-6}$ torr using two tungsten filaments for codeposited mixed films. Figure 1 gives the schematic diagram of the arrangement for deposition of mixed films and single films in the same vacuum cycle. The two materials were in the ratio $1: 1$ by weight. The twc sources were kept opposite to each other at a distance of $10 \mathrm{~cm}$. A metal partition was kept between the two sources to avoid 


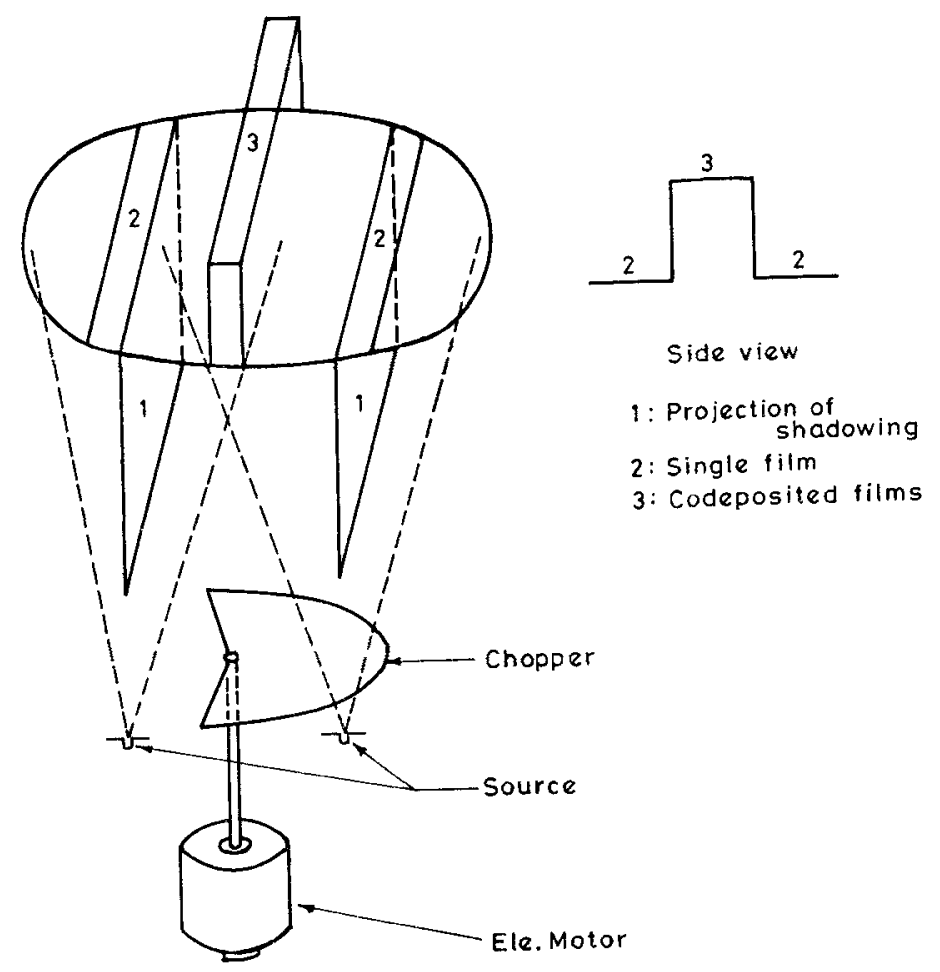

Figure 1. Schematic diagram of substrate holder along with chopper.

contamination of source. The height of the substrate holder was adjusted such that both codeposited mixed and single films had the same thickness. The substrates were glass slides maintained at room temperature during deposition. The thickness of the films was in the range $500-2500 \AA$. The chopper was a circular metallic vane with a $V$-shaped cutout kept above the evaporation source (figure 1) giving a chopping rate of 5-6 rot $/ \mathrm{sec}$. The adhesion was measured by direct pulloff(DPO) method by sticking aluminium studs of $0.5 \mathrm{~cm}$ diameter to the film surface and back of substrate and pulling by tensile testing machine until fracture occurred at the interface. The error in the measurement using the adhesion testing machine (Puri et al 1991) was $\pm 9 \cdot 81 \mathrm{kgF} / \mathrm{cm}^{2}$.

\section{Results and discussion}

The typical values of adhesion of codeposited mixed metallic and dielectric films as a function of thickness are shown in figures 2 and 3 respectively. Table 1 gives the average values of adhesion of codeposited mixed and single films. From the graphs and table it is seen that there is an appreciable increase in adhesion of the codeposited mixed films due to chopping. An interesting result is that non-chopped mixed films show higher adhesion than non-chopped single films, the exception being Al. Both metallic and dielectric films of thickness $>1000 \AA$ show near-saturation effect as 


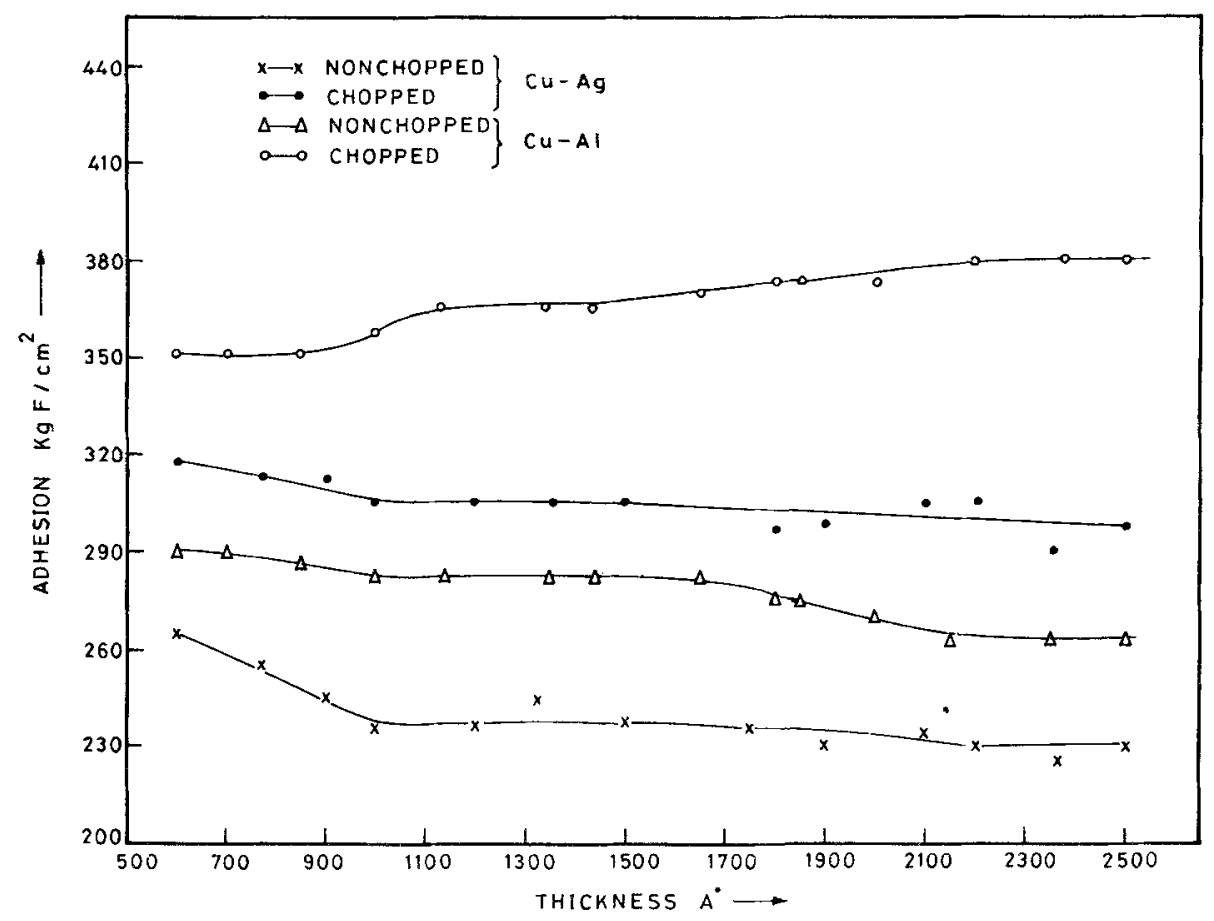

Figure 2. Typical values of adhesion vs thickness of codeposited mixed metallic films.

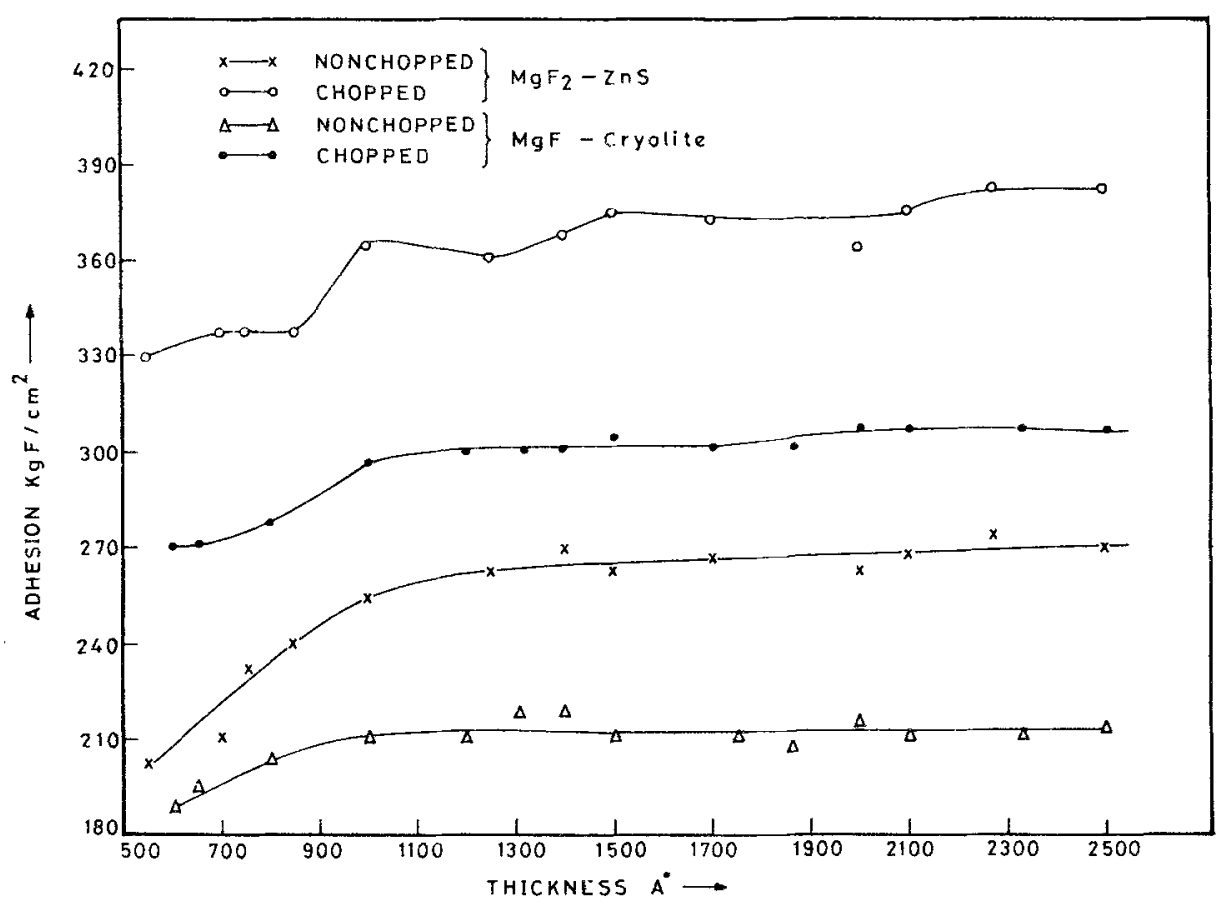

Figure 3. Typical values of adhesion vs thickness of codeposited mixed dielectric films. 
Table 1. Average values of adhesion of codeposited mixed and single films.

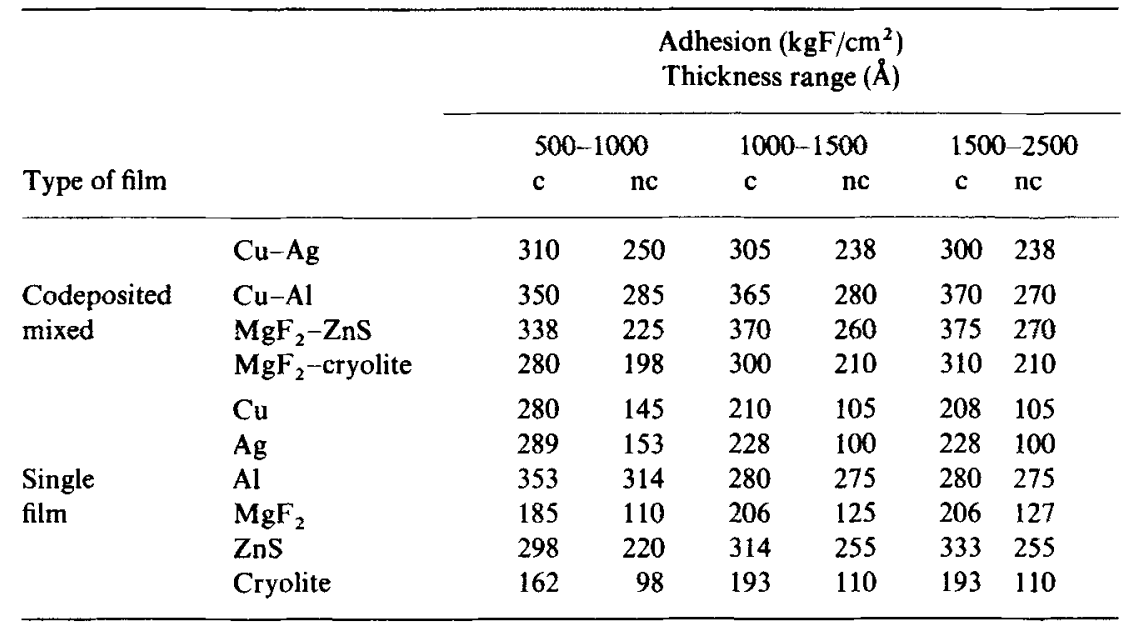

C, Chopped; nc, non-chopped.

adhesion does not change appreciably with thickness. From figure 3 it is seen that thinner dielectric films have lesser adhesion than thicker films.

During codeposition a pseudodiffusion type of interface might be formed (Mattox and Rigney 1986) which might be the cause of enhanced adhesion of codeposited mixed films. It has been reported (Jacobson 1966) that evaporated mixtures have a finer structure than that of the individual materials. The films of $\mathrm{Ag}, \mathrm{Al}, \mathrm{MgF}_{2}, \mathrm{ZnS}$ and cryolite have been observed to have columnar microstructures (Guenther and Jung 1976; Pulkar 1982).

During the process of chopping there is a continuous growth flux interruption. Due to this interruption there is a quenching of the columnar crystal growth. It has been reported (Ogura 1975) that pseudoboundaries are formed when there is a discontinuity in the rate of deposition. Formation of pseudoboundaries leading to pseudodiffusion becomes more prominent if two materials are codeposited and chopped giving more adherent films.

The chopping process also enhances surface mobility of adatoms whereby the defects are not frozen at the site of impingement. Due to the arrival of two adatoms of different species during codeposition the number of nucleation sites increases and constant flux interruptions prevent growth of large crystallites. Also due to the presence of different species there are chances of recrystallization thereby ordering the film microstructure. The net effect of these processes is to decrease the voids in the film due to latetal surface diffusion and change in the columnar morphology of the films. Since defects are not frozen and there is a decrease in grain size due to chopping, fractures do not propagate for large distances in the film. These contribute to the increase in adhesion of the film. Enhanced adhesion due to increased mobility, decreased void density and lateral surface diffusion has been reported (Martin et al 1983) for deposition on heated substrate. Our values of adhesion of chopped single films compare very well with those of deposition on heated substrate (Vijaya et al 1993). 
Another process dominant while chopping is to assist the affinity of adatoms to oxygen. Our electron diffraction (Puri et al 1983) data for $\mathbf{M g F}_{2}$ and cryolite show the presence of oxide in a complex form in the chopped films. The ESCA of $\mathrm{MgF}_{2}$ and $\mathrm{CeO}_{2}$ (unpublished work) also show excess oxygen in chopped films. Excess oxygen has been reported (Laugier 1981) to decrease stress in films. Decrease of stress increases the adhesion (Jacobs et al 1986). This oxygen incorporation mechanism is more dominant in chopped metallic films, except single aluminium films. Aluminium being an oxygen active metal, during deposition oxygen migration takes place in the Al-glass interface forming a bonding layer (Laugier 1981). The chopping process does not seem to enhance this effect in $\mathrm{Al}$, since single chopped $\mathrm{Al}$ films do not show appreciable increase in adhesion compared to non-chopped films. Chopped $\mathrm{Cu}-\mathrm{Ag}$ films show an appreciable increase in adhesion indicating the presence of interfacial bonding layer. The presence of excess oxide is also shown in DC resistivity data of these films (Vijaya et al 1993). The DC resistivity of chopped copper is $3.97 \mu \mathrm{ohm} \mathrm{cm}$ and that of non-chopped copper $1.89 \mu \mathrm{ohm} \mathrm{cm}$, whereas for nonchopped and chopped aluminium the values are 5.2 and $5.6 \mu \mathrm{ohm} \mathrm{cm}$ respectively. It has been reported (Sun 1973; Nagano 1980; Craig and Harding 1981) that there is a reduction in grain size and change in morphology due to increase in DC resistivity. These facts give validity to the argument that due to chopping there is change in morphology of the films, a decrease in grain size and enhancement of oxygen affinity. The refractive index and packing density of chopped films are higher than those of non-chopped films (Puri et al 1983) indicating a close packed structure formation due to chopping.

A combination of all the above processes seems to be operating in chopped films which is more effective when mixed films are codeposited, the net effect being increase in adhesion of the film.

\section{Conclusions}

Our studies indicate that mixing by codeposition gives films with better adhesion than single films, the process of chopping enhancing this. The chopping process seems to increase surface mobility, reduces defects and decreases grain size, whereby quenching of crystal growth takes place due to which a more compact film structure is obtained which increases the adhesion of the films. The presence of two different adatom species during codeposition enhances the above effect. Increase in oxygen affinity also seems to be a very dominant effect of chopping.

Chopping along with mixing by codeposition might give wide scope for tailoring of film properties both for microelectronics and optical purposes. The fact that chopped codeposited mixed films age the least (Vijaya et al 1987) and that chopped mixed films have higher adhesion indicate the use of chopping technique as a technologically useful process for functional coatings. Non-destructive analysis of the interface may give better insight into the adhesion process due to chopping.

\section{Acknowledgement}

One of the authors (VP), gratefully acknowledges the award of Research Scientist by the University Grants Commission, New Delhi. 


\section{References}

Craig S and Harding G L 1981 J. Vac. Sci. Technol. 19205

Fancey K S and Mathews A 1990 IEEE Trans. Plasma Sci. 18869

Ganner P 1986 Proc. SPIE. 65269

Guenther H K and Jung E 1976 Thin Solid Films 4219

Hiradayanath R, Chopra K N and Grover O P 1979 Appl. Opt. 183328

Jacobs S D, Hrycin A L, Cerqua K A, Kennemore C M and Gibson U J 1986 Thin Solid Films 14469

Jacobsson R 1966, 1975 Physics of thin films (Academic Press) Vol. 3, Vol. 8 pp. 2 and 53

Laugier M 1981 Thin Solid Films 7915

Martin P J, Macleod H A, Netterfield R P, Pacey C G and Sainty W G 1983 Appl. Opt. 22178

Mattox D M 1973 Thin Solid Films 18173

Mattox D M and Rigney D A 1986 Mater. Sci. Eng. 83189

Nagono J 1980 Thin Solid Films 671

Ogura S 1975 Ph. D. Thesis, New Castle upon Tyne Polytechnic, UK

Pierce R W and Vaugham J G 1983 IEEE CHMT. 6202

Pulkar H K 1982 Thin Solid Films 89191

Pulkar H M, Reinhold M and Esposito R 1990 Laser Optron. 951

Puri R K, Vijaya K and Karekar R N 1983 Pramana - J. Phys. 21311

Puri R K, Puri Vijaya and Mali S A 1991 Proc. IVSNS. 354

Stoddart C T H, Clarke D R and Robbie C J 1970 J. Adhesion 2270

Sun R C 1973 J. Appl. Phys. 441099

Vankar V D, Pandya D K and Chopra K L 1979 Thin Solid Films 5943

Vijaya Puri and Puri R K 1993 Jpn. J. Appl. Phys. 32, 104699

Vijaya K, Puri R K and Karekar R N 1980 Thin Solid Films 70105

Vijaya K, Puri R K and Karekar R N 1987 Pramana-J. Phys. 28277 